\title{
Moderate Mitral Regurgitation with CABG in EF 40 or Less: To Repair or Not to Repair?
}

\author{
YASSER MENEISSY, M.D. and SAMY AMIN, M.D. \\ The Department of Cardiothoracic Surgery, Kasr El-Eini, Faculty of Medicine, Cairo, Egypt
}

\begin{abstract}
Background: The presence of Ischemic Moderate Mitral Regurgitation in patients with ejection fraction 40 or less undergoing CABG surgery is still controversal. Should the mitral valve be repaired or is the CABG surgery sufficient to correct this regurgitation?
\end{abstract}

Aim of Study: This study was conducted to compare the echocardiographic and the clinical outcome of those patients after 2 years post-operatively.

Patients and Methods: This study was conducted from 2011 to 2014. Sixty patients with ischemic moderate MR were studied. They were randomly divided into 2 groups: Group A were 30 patients who underwent mitral valve repair together with CABG while Group B were 30 patients who underwent CABG only. Both groups were demographically similar to each other.

Results: Group A patients had a significantly improved functional capacity, reversed left ventricular remodeling and reduced degree of mitral regurgitation. The 2 year freedom from cardiac related events leading to death among patients of Group A and B was $92.1 \% \pm 1.5 \%$ versus $85.3 \% \pm 2.1 \%$ ( $p$ value $<0.05$ ). Ischemic mitral regurgitation affects significantly survival in patients with ejection fraction $40 \%$ or less. Ischemic mitral regurgitation promotes left ventricular remodeling in all patients. Among the 25 patients with moderate MR in Group B, 18 patients $(60 \%)$ moved from moderate to severe MR at 2 years follow-up.

Conclusions: Ischemic mitral regurgitation significantly increases the incidence of cardiac related deaths among patients with ejection fraction $40 \%$ or less. 18 patients $(60$ who had moderate MR progressed to severe MR.

Key Words: Coronary heart disease-Coronary artery bypass surgery-Moderate ischemic mitral regurgitation - Impaired left ventricular function.

\section{Introduction}

ISCHEMIC Mitral Regurgitation (IMR) can be defined as Mitral Valve (MV) insufficiency caused

Correspondence to: Dr. Yasser Meneissy, The Department of Cardiothoracic Surgery, Kasr El-Eini, Faculty of Medicine, Cairo, Egypt by coronary artery disease and excluding other causes of mitral pathology. It usually occurs with right or circumflex coronary infarction [1]. The management of moderate IMR stilldebatable as some studies showed that uncorrected mitral regurgitation leads to increase post-operative morbidity and mortality while others claim that mitral valve surgery may add to the operative risk when combined with revascularization. The optimal strategy for treatment of moderate IMR is not yet known [2].

\section{Patients and Methods}

The study was done at the Cardio-Thoracic Surgery Department, Kasr El-Aini Hospital, Cairo University, in the period between 2011 and 2014. 60 patients with IHD, ejection fraction 40 or less with moderate ischemic mitral regurge undergoing CABG will be included in the study. They were randomly divided into 2 groups: Group A were 30 patients who underwent mitral valve repair together with revascularization while Group B were 30 patients who underwent revascularization only. The study was approved by the Ethics Committee for Clinical Research of the institutions. Informed written consent was received from all participants of the study.

All patients were evaluated thoroughly preopertaine, intraoperative and post-operative with special attention to pre-operative echocardiographic finding, long term follow-up of the ventricular functional capacity, ventricular remodeling, degree of mitral regurge and freedom of cardiac related events that might lead to death were recorded.

All the patients had their revascularization on pump CABG. As for Group A, mitral repair is been done by rigid incomplete carpentier-edward. All patients were evaluated thoroughly during their 
Intensive Care Unit stay, during their hospital stay and following them up. Results were summarized using mean, standard deviation, minimum and maximum and number (percent). Data were coded and entered using the statistical package SPSS computer program (Version 21 windows) (IBM Inc., Chicago, Illinois, USA).

\section{Results}

Patients' baseline pre-operative characteristic analyses did not reveal any significance between groups (Table 1$)$. There were 20 males $(66.66 \%)$ in Group (A) and 10 females (33.33\%) as compared to $24(80 \%)$ males and $6(20 \%)$ females in Group (B). The mean age for Group (A) was $65.0 \pm 2.4$ and for Group (B) 66.0 1.6 .13 patients (43.33\%) in Group A had dyspnea NYHA class II and 17 patients $(56.66 \%)$ had dyspnea NYHA class III, while in Group B, 12 patients $(40 \%)$ presented with dyspnea NYHA class II and 18 patients $(60 \%)$ with dyspnea NYHA class III.

Table (1): Pre-operative characteristic analyses of the two studied groups.

\begin{tabular}{lllr}
\hline & Group A & Group B & $p$-value \\
\hline Age (years) & $65.0 \pm 2.4$ & $66.0 \pm 1.6$ & 0.063 \\
Sex: & & & \\
$\quad$ Males & $20(66.66 \%)$ & $24(80 \%)$ & 0.243 \\
$\quad$ Females & $10(33.33 \%)$ & $6(20 \%)$ & \\
NYHA: & & & \\
$\quad$ II & 13 & 12 & \\
III & 17 & 18 & \\
Echo: & & & \\
$\quad$ LVED & $6.6 \pm 0.5$ & $6.7 \pm 0.22$ & 0.071 \\
LVES & $5 \pm 0.5$ & $5.1 \pm 0.12$ & 0.112 \\
LA & $4.8 \pm 0.08$ & $4.9 \pm 0.12$ & 0.061 \\
EF\% & $38 \pm 2.0$ & $37 \pm 2.0$ & 0.059 \\
\hline
\end{tabular}

Smooth weaning off bypass was achieved in 18 patients $(60 \%)$ of Group A and 16 patients $(53.33 \%)$ in Group B ( $p=\mathrm{NS})$. The rest of the patients needed either, inotropic support and or electric cardioversion. No need for IABP to achieve weaning. The right coronary artery or its posterior descending branch was grafted in 25 patients $(83.33 \%)$ in Group A and 23 patients (76.66\%) in the Group B.

Table (2): Intraperative characteristic analyses of the two studied groups.

\begin{tabular}{llll}
\hline & \multicolumn{1}{c}{ Group A } & \multicolumn{1}{c}{ Group B } & $p$-value \\
\hline Total bypass time & $83.0 \pm 19.0$ & $91.1 \pm 19.3$ & 0.110 \\
Cross clamp time & $55.45 \pm 14.76$ & $64.77 \pm 13.6$ & 0.055 \\
Operation time & $199.34 \pm 11.00$ & $205 \pm 12.1$ & 0.06 \\
Use of inotropes & $12(40.0 \%)$ & $14(46.66 \%)$ & 0.794 \\
Electric cardioversion & $7(23.33 \%)$ & $9(30.0 \%)$ & 0.770 \\
\hline
\end{tabular}

The post-operative course has been recorded in (Table 3). Patients were discharged from the ICU when haemodynamically stable on no inotropic support, with no drains, and with satisfactory postoperative laboratory results and ECG.

Table (3): Post-operative charactarestics of the study groups.

\begin{tabular}{llll}
\hline & Group A & Group B & $\begin{array}{c}p \text { - } \\
\text { value }\end{array}$ \\
\hline Mechanical ventilation, (hrs) & $13.0 \pm 4.8$ & $15.3 \pm 4.6$ & 0.105 \\
Inotropic support (hrs) & $20.72 \pm 13.05$ & $24.9 \pm 12.71$ & 0.783 \\
Total icu stay (hrs) & $41.0 \pm 7.2$ & $44.0 \pm 7.6$ & 0.122 \\
Reexploration for bleeding & 3 & 5 & 0.704 \\
Chest infection & 2 & 3 & 1.00 \\
Renal failure & 0 & 1 & 1.00 \\
Mediastinitis & 1 & 2 & 1.00 \\
\hline
\end{tabular}

Echocardiography was done for all the patients 1 week, $6 \mathrm{~m}, 1$ year and 2 years post-operatively. In assessing the patients ventricular functional capacity, ventricular remodeling the following was found that there were significant improvement in Group A dimensions and functions. The 2 year freedom from cardiac related events leading to death among patients of Group A was $92.1 \% \pm 1.5 \%$ and in Group B was $85.3 \% \pm 2.1 \%$ ( $p$-value $<0.05$ ). Among the patients with in Group B, 18 patients $(60 \%)$ moved from moderate to severe MR at 2 years follow-up.

Table (4): Comparison between pre-operative and post-operative echocardiographic data.

\begin{tabular}{|c|c|c|c|c|c|c|c|c|c|c|c|c|}
\hline & \multicolumn{5}{|c|}{ Group A } & \multicolumn{5}{|c|}{ Group B } & \multicolumn{2}{|c|}{$p$-value } \\
\hline & \multirow{2}{*}{ Pre-op. } & \multicolumn{4}{|c|}{ Post-operative } & \multirow{2}{*}{ Pre-op. } & \multicolumn{4}{|c|}{ Post-operative } & \multirow{2}{*}{$\begin{array}{l}\text { Pre- } \\
\text { op. }\end{array}$} & \multirow{2}{*}{$\begin{array}{c}\text { Post- } \\
\text { op. }\end{array}$} \\
\hline & & $1 \mathrm{w}$ & $6 \mathrm{~m}$ & $1 y$ & $2 y$ & & $1 \mathrm{w}$ & $6 \mathrm{~m}$ & $1 y$ & $2 \mathrm{y}$ & & \\
\hline LVED & $6.6 \pm 0.5$ & $6.42 \pm 0.4$ & $6.2 \pm 0.3$ & $6 \pm 0.1$ & $5.8 \pm 0.25$ & $6.7 \pm 0.2$ & $6.6 \pm 0.08$ & $6.55 \pm 0.7$ & $6.4 \pm 0.7$ & $6.5 \pm 0.01$ & 0.07 & 0.002 \\
\hline LVES & $5 \pm 0.5$ & $4.91 \pm 0.19$ & $4.7 \pm 0.1$ & $4.61 \pm 0.4$ & $4.5 \pm 0.2$ & $5.1 \pm 0.2$ & $5.05 \pm 0.3$ & $5 \pm 0.04$ & $4.97 \pm 04$ & $4.95 \pm 0.5$ & 0.11 & 0.003 \\
\hline LA & $4.8 \pm 0.08$ & $4.5 \pm 0.06$ & $4.4 \pm 0.4$ & $4.3 \pm 0.08$ & $4.2 \pm 0.04$ & $4.9 \pm 0.2$ & $4.8 \pm 0.04$ & $4.7 \pm 0.3$ & $4.65 \pm 0.3$ & $4.6 \pm 0.3$ & 0.06 & 0.002 \\
\hline $\mathrm{EF} \%$ & $38 \pm 2.0$ & $41.9 \pm 2.0$ & $44.5 \pm 0.7$ & $46.4 \pm 1.0$ & $47.5 \pm .02$ & $37 \pm 2.0$ & $37.9 \pm 2.0$ & $38.5 \pm 0.1$ & $3903 \pm 0.4$ & $39.9 \pm 0.6$ & 0.059 & 0.001 \\
\hline
\end{tabular}


At 2-year follow-up, the mortality increased in patients undergoing isolated CABG in Group B versus patients undergoing combined surgery in Group A. Mortalities in Group A were 4 ( 2 of Congestive heart failure $6.6 \%$ ), 1 of sudden death (3.3\%) and 1 of arrhymias (3.3\%) while in Group B they were 6 ( 3 of congestive heart failure 10\%), 1 of sudden death $(3.3 \%)$ and 1 of arrhymias $(3.3 \%)$ and 1 of renal failure $(3.3 \%)$.

\section{Discussion}

Ischemic MR is caused because of dilatation of the mitral annulas with altered ventricular shape, myocardial ischemia leading to dilatation of the left ventricle and impairment of ventricular contractility which leads to restriction of the leaflet mobility and papillary muscle infarction which causes valve prolapse [3]. Mitral regurge causes volume overload, left ventricular remodeling and enlargement, progressive annular dilation, more severe regurgitation which leads to loss of contractile forces and congestive heart failure [2]

The pre-operative profile of both patient groups was similar with no statistically significant differences as regards to age, sex, and risk factors for IHD, clinical status, and preoperative investigations. It was also similar to patients investigated in other studies [4]

In the study by Lam et al., [4] 53\% of their patients had moderate to severe LV dysfunction (EF $<40 \%)$ as compared to all in our series. The series by Tolis and colleagues was essentially conducted on patients with ischaemic cardiomyopathy (mean $\mathrm{EF}=22 \%$ ) and also included patients with 3 + IMR.

$83.3 \%$ of the patients in Group A had a previous posteroinferior infarction and $86.7 \%$ of the patients in Group B had a previous posteroinferior infarction. This validates data by other authors that states that, although anterior infarctions are common to occur in IHD patients, the occurrence of IMR is more common after a posteroinferior myocardial infarction [4]. In their series on 102 patients with IMR, Calafiore and colleagues found that a posterior or inferior myocardial infarction occurred in $61.3 \%$ of their patients [5]. This could be explained by appreciating the blood supply of the papillary muscles supporting the mitral valve apparatus.

We found no correlation between the preoperative left atrial size and the presence of moderate IMR. This was not expected finding because the Left Atrium (LA) is exposed to LV filling.
Tsang et al., have demonstrated the close association between LV diastolic function and LA volume, which provides a sensitive physiologic expression of the severity of LV diastolic dysfunction and appears to be a useful index of cardiovascular risk [6]

The operative results of our two studied groups were similar. There were no statistically significant differences as regards the total bypass and ischaemic times, weaning off bypass, the dosage or length of time patients were on inotropic support, the need for IABP counterpulsation, the period of mechanical ventilation, the total blood loss, the perioperative morbidity or mortality, and the total period of ICU or hospital stay. Those results were close to the results obtained by Bhudia et al., [7].

The ICU course (duration of mechanical ventilation, inotropes/hour, ICU stay of both groups) showed no statistical difference. This is similar to the results obtained by Tolis and colleagues [8]. In their patients, the ejection fraction improved from $22.0 \%$ to $31.5 \%(p<0.05)$ after CABG. The mean degree of MR improved with $\mathrm{CABG}$ alone from 1.73 to $0.54(p<0.05)$ as measured at a mean interval of 36.9 months from CABG. New York Heart Association congestive heart failure class improved from 3.3 to $1.8(p<0.05)$ [9]

In our study, the cumulative survival and freedom from cardiac related events that leads to death in patients with moderate mitral regurge and ejection fraction less then 40 or less undergoing revascularization and mitral repair in Group A was significantly higher versus patients with the same criteria doing revascularization alone in Group B. The 2 year freedom from cardiac related events leading to death among patients of Group A and B was $92.1 \% \pm 1.5 \%$ versus $85.3 \% \pm 2.1 \%$ ( $p$-value $<0.05$ ). Different studies demonstrated that residual moderate mitral regurge is a strong predictor for poor surviva1 [10]. Czer et al., demonstrated that doing annuloplasty with coronary artery bypass grafting reduced regurgitation remarkebely by achieving a normal relationship between the annulus sizes and the leaflet, while revascularization alone was insufficient [11]. Other authors demonstrated that moderate mitral regurge is a strong predictor for poor survival in left ventricular function impairement patient treated by revascularization alon [12]. On the other hand, Christenson et al., reported good survival and morbidity in patients with poor left ventricular function impairement patient and moderate mitral regurge undergoing revascularization alone and reporting absence of regurge post-operatively [13]. Duarte et al., 30 
reported acceptable outcome with their patients having ischemic moderate mitral regurge with ejection fraction less then 40 or less undergoing revascularization alone [14]

Left ventricular functional capacity, reversed ventricular remodeling and residual regurge improved significantly in Group A undergoing combined surgery, whereas patients undergoing isolated revascularization had higher degree of residual regurge after surgery, improper left ventricular remodeling, and minimal dimension improvement post-operatively. This was similar to other studies that reported statistacilly significant difference between their 2 groups undergoing revascularization alone and revascularization with mitral repair [12]

Post-operatively, NYHA class improved significantly in bothgroups, but patients undergoing isolated revascularization remained in a higher NYHA class versus patients undergoing combined surgery but the difference between the 2 groups was insignificant. This was different from other studies that reported statistacilly significant difference between their 2 groups undergoing revascularization alone and revascularization with mitral repair where they repoted in combined surgery group NYHA class improved significantly higher than but patients undergoing isolated CABG probably due to long-standing MR causing a progressive myocardial fibrosis [12].

Echocardiographic analysis in our study, between the 2 groups demonstrated a significant LV dimension and function improvement in Group $\mathrm{A}$ patients. It seems that revascularization alone for moderate MR improves the contractile function, yet not as the similar of post-operative contractility in patients versus patients undergoing combined surgery, even though LV dimension and geometry are not improved as much as in patients undergoing concomitant MR correction. Also the progression of the regurge significantelly appeared in Group B patients where 18 patients from this group (60\%) who had moderate MR progressed to severe MR. This was similar to the results of others [2].

In our study, at 2-year follow-up, the mortality were higher in Group B patients undergoing isolated revascularization versus patients undergoing combined surgery however the difference was statistacilly insignificant. This was different from other studies that reported statistacilly significant difference between their 2 groups undergoing revascularization alone and revascularization with mitral repair [2].

\section{Conclusion:}

Ischemic mitral regurgitation significantly increases the incidence of cardiac related deaths among patients with ejection fraction $40 \%$ or less. $60 \%$ of patients who had moderate MR progressed to severe MR. Correction of ischemic moderate.

Mitral regurge in patients with impaired LV function should be taken into consideration causes better survival and improvement of left ventricular remodeling and performance compared with patients undergoing isolated revascularization alone.

Limitations: Bigger sample size, availability of transoesophageal echo to asses the jet area once get off bypass and availability echo in the ICU to asses the patients before ICU discharge, more frequent echo follow-up of the patients to be done every 6 month.

\section{References}

1- DIODATO M.D., MOON M.R., PASQUE M.K., et al.: Repair of ischaemic mitral regurgitation does not increase mortality or improve long-term survival in patients undergoing coronary artery revascularization; a propensity analysis. Ann. Thorac. Surg., 78: 794-9, 2004.

2- CARMELO A. MILANO, MANI A. DANESHMAND, J. SCOTT RANKIN, EMILY HONEYCUTT, MATTHEW L. WILLIAMS, et al.: Survival prognosis and surgical management of ischemic mitral regurgitation. Ann. Thorac. Surg., 86: 735-44, 2015.

3- KONO T., SABBAH H.N., ROSMAN H., et al.: Left ventricular shape is the primary determinant of functional mitral regurgitation in heart failure. J. Am. Coll. Cardiol., 20: 1594-8, 2012.

4- LAM B.K., GILLINOV A.M., BLACKSTONE E.H., et al.: Importance of moderate ischaemic mitral regurgitation. Ann. Thorac. Surg., 79: 462-70, 2005.

5- KUMANOHOSO T., OTSTIJI Y., YOSHIFUKU S., et al.: Mechanism of higher incidence of ischaemic mitral regurgitation in patients with inferior myocardial infarction: Quantitative analysis of left ventricular and mitral valve geometry in 103 patients with prior myocardial infarction. J. Thorac. Cardiovasc. Surg., 125: 135-43, 2003.

6- CALAFIORE A.M., Di MAURO M., GALLINA S., et al.: Mitral valve surgery for chronic ischaemic mitral regurgitation. Ann. Thorac. Surg., 77: 1989-97, 2004.

7- TRICHON B.H., FELKER G.M., SHAW L.K., et al.: Relation of frequency and severity of mitral regurgitation to survival among patients with left ventricular systolic dysfunction and heart failure. Am. J. Cardiol., 91: 53843, 2003.

8- BHUDIA S.K., McCARTHY M.M., SMEDIRA N.G., et al.: Edge-to-edge (Alifieri) mitral repair. Ann. Thorac. Surg., 77: 1598-606, 2004.

9- TOLIS G.A. Jr., KORKOLIS D.P., KOPF G.S., et al.: Revascularization alone (without mitral valve repair) 
suffices in patients with advanced ischaemic cardiomyopathy and mild to moderate mitral regurgitation. Ann. Thorac. Surg., 74: 1476-80; discussion 1480-1, 2002.

10- HAUSMANN H., SINIAWSKI H. and HETZER R.: Mitral valve reconstruction and replacement for ischemic mitral insufficiency: Seven years' follow-up. J. Heart Valve Dis., 8: 536-42, 2011.

11- CZER L.S., MAURER G., BOLGER A.F., et al.: Revascularization alone or combined with suture annuloplasty for ischemic mitral regurgitation. Evaluation by color Doppler echocardiography. Tex. Heart lnst. J., 23: 2708, 2016.
12- PRIFTI E., BONACCHI M., FRATI G., et al.: Early and midterm outcome of coronary artery bypass grafting in end-stage coronary artery disease patients. Cor. Europaeum., 8: 93-9, 2014.

13- CHRISTENSON J.T., SIMONET F., BLOCH A., et al.: Should a mild-to-moderate mitral valve regurgitation in patients with poor left ventricular function be repaired or not? J. Heart Valve Dis., 4: 484-8, 2005.

14- DUARTE I.G., SHEN Y., MacDONALD M.J., et al.: Treatment of moderate regurgitation and coronary disease by coronary bypass alone: Late results. Ann. Thorac. Surg., 68: 426-30, 2012.

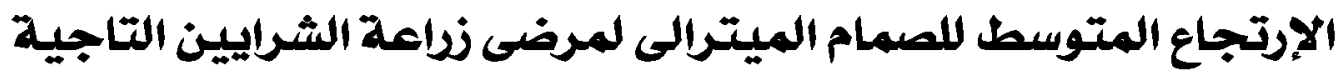

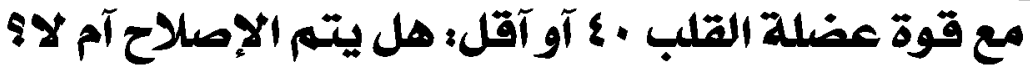

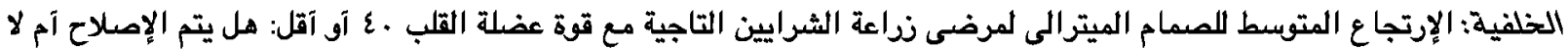

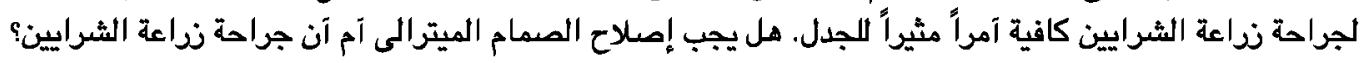 \\ الهدف من الدراسة: آجريت هذه الدراسة لمقارنة تخطيط صدى القلب والنتائج السريرية لهؤلاء المرضى بعد ب سنوات بعد العمل الجراحى.

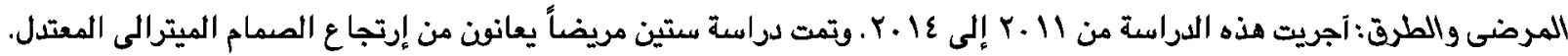

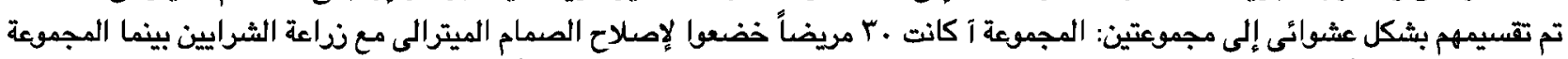

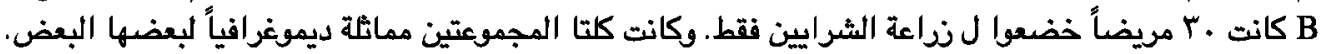

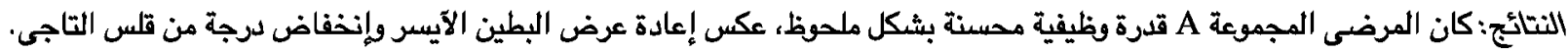

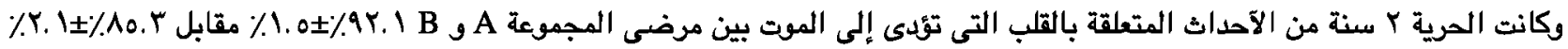

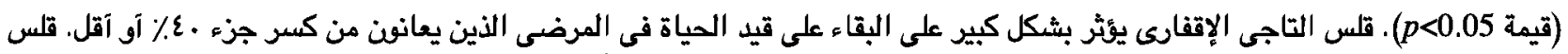

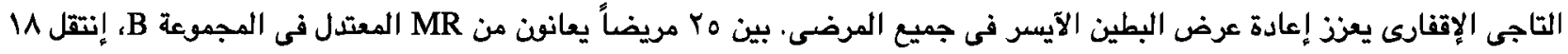

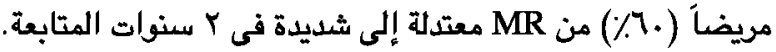

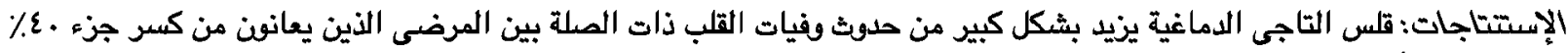

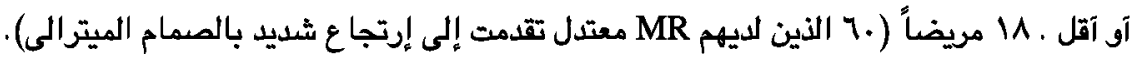

